\title{
DRUG OFFENCE DETECTION DURING THE PANDEMIC: A SPATIOTEMPORAL STUDY OF DRUG MARKETS
}

\author{
A PREPRINT
}

\author{
Jason L. Payne* \\ School of Health and Society \\ University of Wollongong
}

\author{
Cameron T. Langfield \\ School of Health and Society \\ University of Wollongong
}

June 2021

\begin{abstract}
Purpose: Research on COVID-19 and crime has so far shown that most crime types declined, especially in the early months of the pandemic. Illicit drug offences were a notable exception, however few studies have considered changes at specific drug market locations. This study documents how key drug markets were affected during the lockdown.

Methods: Using a spatiotemporal generalised additive model (GAM), this study examines the pattern of drug offence detection throughout the city of Brisbane, Australia and identifies areas of change during lockdown. Statistical meshblock analysis is used to illustrate discrete changes at key market locations.

Results: Contrary to aggregate-level analysis, we show that several of the major drug markets experienced a significant decline in drug offence detections, but that these local changes were offset by a displacement to neighbouring areas. We also find some preliminary evidence of the emergence of new outer-urban markets.

Conclusions: Existing drug markets were adversely affected by the COVID-19 lockdown, however drug market activity was likely displaced rather than diminished.
\end{abstract}

Keywords: COVID-19; drug markets; drug offence detections; pandemic; Brisbane Australia

\section{Introduction}

The extant empirical analysis of COVID-19 and crime has, to date, pointed to a surprising increase in drug offence detections (Andresen and Hodgkinson, 2020; Langfield et al., 2021) despite a decline in most other property and violent crimes (Ashby, 2020a, 2020b; Campedelli, Aziani, et al., 2020; Campedelli, Favarin, et al., 2020; Nivette et al., 2021; Payne et al., 2020, 2021; Piquero et al., 2021). Although much of this analysis has focused on state- or city-wide aggregations, the conclusion thus far is that drug markets have been relatively unaffected by this once-in-a-generation event, which is surprising given the pandemic's unprecedented impact on routine activities and pedestrian mobility (O'Sullivan et al., 2020; Stickle and Felson, 2020). Contemporary drug markets are not what they used to be, to be sure, and mobile communication technologies have certainly changed how many drug users and drug sellers interact (Barendregt et al., 2006; Curtis et al., 2002; May and Hough, 2004). But, street markets continue to thrive in many big cities and we should expect that the social distancing regulations associated with COVID-19 will have interrupted markets at these sites even if that local effect is masked in city-wide aggregations and trends.

In this study, we drill down into the drug offence detection data for several key drug markets in Brisbane, the capital city of Queensland, Australia. We follow what happens in each area during the first six months of 2020 and we compare prelockdown (January-March) and lockdown data (April-June), noting that the Queensland Government ordered the closure of nonessential businesses and imposed restrictions on non-essential travel and social activities on March 24 (Queensland Government, 2020a). We explore the data at the smallest available geospatial statistical unit in Australia - otherwise known as 'Meshblocks' (Australian Bureau of Statistics, 2011).

\footnotetext{
${ }^{*}$ Corresponding author: jason.payne@uow.edu.au
} 


\section{Drug Markets}

Accessibility and participant mobility have long been identified as key to the emergence and long term success of established street-level drug markets (see Adler, 1993; Agar, 1973; Eck, 1995). In their analysis in Washington DC in 1992, for example, Reuter and MacCoun made a clear distinction between four different market typologies. They called them Local Markets, Import Markets, Export Markets and Public Markets, and they distinguished between them using different models of participant mobility in an effort to define who travels where, and why. Although somewhat limited in its capacity to describe contemporary, technologically connected market networks, still the framework is useful for understanding how different street-markets evolve and it reminds us that accessibility is key to their success and persistence (see the work of L. T. Johnson, 2009, 2016 for empirical tests of this typology).

The Local Market, for example, is a place where most transactions occur between buyers and sellers who live close to one another, often within a reasonable proximity to the principal site of transaction. In Local Markets, the distance travelled by both parties is short, often by foot or with minimal use of public transport. The Public Market, on the other hand, is at the other end of the spectrum, describing places of predictable and regular drug transactions but where drug users and drug sellers both travel from farther away to meet. Public Markets are said to develop at key locations of pedestrian intersection, usually where multiple public transport routes combine at transit hubs or major commuter interchanges.

Between Local and Public markets are the two other types of drug market described by Reuter and MacCoun (1992). These are Import Markets and Export Markets and these are locations where only one party to the transaction is from outside the principal area of exchange. The Import Market, for example, is said to be a location where the dominant transaction is between drug sellers who travel in to supply a local resident population of drug users, essentially importing drugs into a market of willing consumers. Conversely, Export Markets are those locations where the dominant transaction depends on drug users travelling to meet drug dealers near where the dealers live, essentially then 'exporting' their purchase from the market and back to their home.

Reuter and MacCoun (1992) are but two of a number of scholars who have similarly attempted to describe street-level drug markets, though, again, accessibility and mobility feature heavily in these efforts to differentiate (see, for example, Buerger, 1991; Curtis and Wendel, 2000; Dorn et al., 1992; B. Johnson et al., 1992). For example, Johnson and colleagues (1992) postulated that there were two basic types of illicit drug market, namely 'freelance' and 'business' markets. The business market, they suggested, was organised and hierarchical in nature while the freelance market was characterised by low-level dealers who operate within a limited and informal structure and where drug transactions are mostly unplanned and incidental to the available opportunities. For this reason, spatial predictability and accessibility in freelance markets is key to ensuring that drug buyers can easily locate and transact with those who are selling. Similarly, Curtis and Wendel (2000) differentiate drug markets based on two overarching principles: technical and social organisation. Specifically, Curtis and Wendel (2000) argue that drug markets can be technically differentiated into three classes-those characterised by mostly street-level sales (where the user and seller meet and transact on the street), indoor sales (where the user and seller meet somewhere secluded to transact), or delivery sales (where the dealer employs a 'runner' to deliver the product to users). In terms of social organisation three levels are said to define the degree of market complexity and range from 'freelance distributor' markets which have very little formal structure or process, 'socially bonded business' markets which have slightly higher levels of hierarchy and order, and 'corporate-style distributor' markets which have the highest level of complexity and organisation.

It is not the intention of the current study to test the plausibility of these different typological approaches, however, together these frameworks speak to the central importance of geospatial predictability, accessibility and participant mobility - three things we might imagine will have been significantly affected during the COVID-19 lockdown. Further, we also think that to the extent that there are different market structures within a city, these should represent different levels of vulnerability to the demands of a lockdown. Some markets are likely to be more entrenched, or 'Local' (Reuter and MacCoun, 1992), and thus more resilient to external shocks. Others might be more heavily reliant on the travel capacity of outsiders and experience a more significant decline when mobility is reduced by mandate. Some might recover quickly as drug buyers soon return to the place where sellers live (Export markets) while others might recover more slowly if the source of supply cannot or will not travel (Import markets). Finally, some markets might disappear altogether if neither the drug buyers or sellers can be guaranteed a successful exchange (Public markets). ${ }^{2}$

\footnotetext{
${ }^{2}$ In their original article, Reuter and MacCoun (1992) explicitly state that local markets are likely the hardest for police to uproot, principally because those who interact in the market know each other, and thus the market can be easily relocated. Similarly, export markets are unlikely to be affected by policing activity, especially if they bring economic advantage to the neighbourhood. Import and public markets are those which are more amenable to a policing intervention, namely because import markets are considered to be economically disadvantageous or 'parasitic markets' (Reuter and MacCoun, 1992, p. 238) and public markets are those where dealers and sellers are strangers, thus making it difficult to locate each other (quickly) in a new location.
} 


\section{COVID-19 and Mobility}

Given the central importance of accessibility and participant mobility to the success and viability of the street-level drug market, and given that different markets are likely structured around different mobility requirements, it seems reasonable to hypothesise some degree of market disruption during the early months of the COVID-19 pandemic. This is especially likely in places such as Queensland, where strict social distancing orders were put in place to halt international and interstate arrivals as well as to temporarily limit non-essential work and social activities (Queensland Department of the Premier and Cabinet, 2020; Queensland Government, 2020a, 2020c). While the use of public transport was not prohibited, there is little doubt that these government mandates significantly reduced pedestrian movement (Google, 2021), especially on public transport and in the inner city which is densely populated by workers in the day and entertainment economy users in the night (Australian Bureau of Statistics, 2021). Anyone fearing infection by SARS-CoV-2 will have likely avoided all forms of public transport (see, for example, Currie et al., 2020), leaving train stations and bus interchanges relatively deserted. For everyone else, the gaze of street-surveillance will likely have become more perceptible, as the once busy streets of a frenetic city no longer offered the camouflage of anonymity among the masses (see Reynald, 2010; St. Jean, 2007).

\section{Current study}

In this study, we focus our attention on the central inner city region of Brisbane known as Statistical Area Level-4 (or SA4-305). SA4-305 has an estimated resident population of 2.2 million and encompasses 33 SA2s and 3,454 meshblocks (see Figures 1 and 2). Our hypothesis is that, contrary to the aggregate story of city-wide increases in drug offence detections (see Langfield et al., 2021), some of the most prominent drug markets in Brisbane will have diminished during the COVID-19 lockdown. We expect that these area-specific declines will have been offset by an increase in the prevalence of incidental drug offence detections elsewhere in the region.

[Figure 1 about here.]

[Figure 2 about here.]

\section{Methodology}

We first explore changes in drug offence detection rates using predictions and Bayesian prediction intervals from a spatiotemporal Generalised Additive Model (GAM). The model was developed for the whole of Brisbane Local Government Area (LGA) and we have reported elsewhere on the LGA-wide results (see Payne and Langfield, 2021). In this paper we focus on the inner city region of Brisbane and we extend the analysis to explore local-level changes in statistical meshblocks - the smallest geospatial unit available for these data. Our data are drawn from the Queensland Government's Open Data Portal (Queensland Government, 2020b) where meshblock-level unit records for all drug offence detections are available for the past 5 years. We have used the full complement of all data that was available at the time of download (from April 2016 to June 2020).

\section{Modelling strategy and outcomes}

Our main model is built within a GAM framework using a Negative Binomial link function ${ }^{3}$ and a spatiotemporal tensor product for the interaction between geography and time. GAM models are a flexible method for capturing non-linear relationships and have recently been used to model the spatiotemporal nature of SARS-CoV-2 infection rates in the UK, for example (see Wood, 2021) ${ }^{4}$. Specifically, geospatial correlation (i.e. the predictable statistical relationship between neighbouring locations) is captured through a spatial thin-plate spline (see Figure 3) and the long term trends and seasonality of the series (i.e. the predictable patterns across the 12 months of each year) are captured through a cubic regression spline. In this case, it is easiest to think of GAM tensor products and splines as 'smoothed' parameters representing non-linear effects (see also Wood, 2017).

Six location-specific covariates were included in the GAM to explain any residual variance not captured in the geospatial correlation. These covariates were: (1) the relative preponderance of businesses providing the Food and Accommodation services; (2) the relative preponderance of businesses catering to Retail services; (3) the relative economic prosperity of local residents; (4) the relative education and occupation status of local residents; (5) the proportion of local residents that are aged between 15 and 24 (i.e. young adults); and (6) the proportion of local residents that were born overseas.

\footnotetext{
${ }^{3}$ We also tested the model with a Poisson distribution. The Poisson model was less efficient at modelling the few areas with unusually large detection rates and so the risk of under-prediction was higher and deemed unacceptable given the objective of the study was to compare actual and predicted drug offence detection rates.

${ }^{4}$ The GAM framework has elsewhere been used to model and predict the spatiotemporal patterns of such things as mean global temperatures (see, for example, Peristeraki et al., 2019).
} 
[Figure 3 about here.]

As for the local business data, we have used SA2 level estimates reported by the Australian Bureau of Statistics (ABS) and scaled these estimates into a relative measure for the Brisbane LGA. Where the relevant measure for an SA2 is coded as zero, this means that the number of businesses in that SA2 is equal to the average of all SA2s in the Brisbane LGA. A value of one (1) indicates an SA2 where the number of businesses is one standard deviation above the average for the region. For economic, education and occupation indicators we use the Index of Economic Resources (IER) and the Index of Education and Occupation (IER) derived by the ABS from the most recent Census of the Population (Australian Bureau of Statistics, 2016). As with the local business data, we have standardised this to the average of all SA2s in the Brisbane LGA such that zero indicates an area where the IER or IEO score was equal to the average score across the region. Finally, we use Census data to measure the number of young adults (aged 15-24) and the number of residents born overseas as percentages of the local population.

For modelling purposes, we execute the analysis on data from April 2016 to March 2020 (48 months), holding out data for the three months when COVID-19 restrictions were in place (April-June 2020). We then use the model parameters to predict the crime rate for each location and each month of the COVID-19 lockdown. Recognising the inevitable presence of prediction uncertainty and the likelihood that the degree of this error will vary from location to location, we use a Bayesian simulation procedure to compute 10,000 simulations of the model predictions at each location. From this we generate $95 \%$ prediction intervals to reflect the range of values within which we should confidently expect the true value to fall had the COVID-19 lockdown not occured. Unlike the ARIMA methods which have so far dominated the COVID-19 and crime literature (see, for example, Ashby, 2020b; Langfield et al., 2021; Payne et al., 2020, 2021), a key advantage of the spatiotemporal GAM procedure is its capacity to simultaneously model spatial and temporal covariances.

The statistical model parameters and model diagnostics are provided in Figure 4. Overall, the model explains approximately $85 \%$ of the variance. Both spatiotemporal smooth terms are statistically significant ( $\mathrm{EDF}=220, p=0.00$ and $\mathrm{EDF}=25, p=0.00)$. This tells us that there is strong spatial correlation which changes both in the long term (trend) and in a predictable seasonal pattern. Of the locations-specific covariates, the model shows that pre-COVID, drug offence detections were higher in locations where there are more retail businesses $(b=0.16, p=0.02)$, and higher in locations with higher levels of economic disadvantage $(b=-0.69, p=0.00)$, but lower in areas with a higher proportion of young adults $(b=-0.05, p=0.00)$ and/or residents born overseas $(b=-0.02, p=0.03)$.

[Figure 4 about here.]

Finally, while our preliminary efforts focus on the results of the GAM for SA2s within the inner city region of Brisbane, we do this as a pretext for more detailed analysis of drug offence detections at the meshblock level. Meshblocks are the smallest geospatial unit of the Australian Statistical Geography Standard (ASGS) and represent areas covering between 500 and 1000 residents, approximately. Where individual results are graphically displayed, the centremost point (in longitude and latitude) is used for each meshblock, although we note that this centremost point will not always reflect the precise location of each drug offence. Our approach is descriptive insofar as we seek to identify changes in the spatial pattern, specifically as they relate to what is known about the relevant areas where changes occur.

\section{Results}

From the GAM model we produced a spatiotemporal prediction for each SA2 in the Brisbane LGA and from this prediction we compare the observed drug offence detection rate to the Bayesian simulated $95 \%$ prediction intervals. To assist with the interpretation of the region-wide results we first illustrate the outcomes of this comparative analysis for four SA2s (see Figure 5) which have been purposely selected to illustrate the different classification outcomes then presented for the whole region in Figure 6. Specifically, the first of our four examples shows data for the SA2 area known as Toowong. Here the actual drug offence detection rate (summed across three months) was higher than the sum of the point estimated predictions. This means that, on average, there were more drug offence detections in Toowong would have (likely) been the case if the COVID-19 lockdown had not been implemented. We also note that for the months of May and June, the actual offence rate exceeded the 95\% prediction interval. This compares to the second of our selected locations (Kelvin Grove) where drug offence detections were higher than predicted, but where none of the three months exceeded the 95\% prediction interval. In location three (Spring Hill) drug offence detections were neither higher than predicted nor were there any months that fell beyond the $95 \%$ prediction interval, while in the fourth location (Wilston) detections were lower than predicted on average across the three months of lockdown, but in one of those months the prediction exceeded the prediction interval.

[Figure 5 about here.]

[Figure 6 about here.] 
Figure 6 summarises the results for all 33 SA2s in the inner city of Brisbane. The grey shaded areas are those where drug offence detections were, on average, higher than predicted during lockdown. The stars indicate areas where for one or more months the detection rate exceeded the prediction interval. Consistent with earlier findings (Payne and Langfield, 2021), there was a general upward trend in drug offence detections, with about half of all SA2s recording at least one month where drug offence detections were significantly higher than predicted.

Another important aspect of the examples provided in Figure 5 is the magnitude of change relative to the worst case prediction. In this case, we define the worst case prediction as the sum of the upper $95 \%$ prediction intervals over three months. Some areas (Toowong, for example) far exceeded the local prediction, while in other areas the increase was more modest. Figure 7 summarises these results, presenting the location specific relative-increase as a percentage above the sum of the upper limit prediction intervals. Across the inner city, there was one location where the actual drug offence detection rate exceeded the worst case prediction by more than $100 \%$ (i.e. more than double). In three locations, the increase was greater than $50 \%$, while in most other locations the increase was less than 50\%. This confirms that the lockdown experience was not consistent across the inner city of Brisbane.

[Figure 7 about here.]

[Figure 8 about here.]

As foreshadowed at the outset, we expect COVID-19 to have had a differential impact at a lower level of geographical resolution, as different drug markets responded to dramatic changes in accessibility and mobility. Figure 8 plots the numerical count of the number of drug offence detections in each meshblock for the three months prior to the lockdown. Figures 9 and 10 plot the numerical change in drug offence detections during the lockdown period. Figure 9 shows the results for the whole SA4 region, highlighting potential new markets in the outer-urban area. Figure 10 focuses on the inner city area and highlights the locations of greatest numerical decline. Note that to provide a clearer resolution we have limited Figure 10 to just those boundaries enveloping the central CBD.

[Figure 9 about here.]

From these figures we note that drug offence detections fell markedly in four locations. In order of magnitude, these were the Bowen Hills Train station and Brisbane showground precinct to the north of the CBD, the Fortitude Valley red-light and nighttime economy precinct, the Roma Street train station precinct, and the Brisbane Casino precinct (see Figure 10). Offsetting these decreases was a complex pattern of local diffusion and displacement. For example, drug offence detections increased considerably in the very heart of the CBD, to the east of Roma Street station and to the north of the Casino precinct. There was also a sizable increase in detections at the Brisbane Central train station as well as a more diffuse increase in the areas surrounding Fortitude Valley. Beyond the CBD (see Figure 9) there were some notable outer-urban pockets to the southwest (Toowong), west (Ashgrove), north-east (Hendra and Doomben), and to the east of the Brisbane River (Kangaroo Point). Overall, however, the increase in Brisbane appears to have been mostly driven by a rather disparate spread of drug detections across the city where a small number of detections were recorded across a much larger number of locations than before the lockdown.

[Figure 10 about here.]

\section{Discussion}

At the outset of this study we remarked on the importance of mobility and accessibility to the functioning of local area drug markets, in particular the persistent and well-entrenched open-air or street level markets. We used this knowledge and the various typologies generated by a number of scholars (Buerger, 1991; Curtis and Wendel, 2000; Dorn et al., 1992; B. Johnson et al., 1992; Reuter and MacCoun, 1992) to predict significant small-area changes in drug offence detections during the COVID19 lockdown. We argued that this was a novel and important inquiry because the extant literature has so far painted a picture of drug-market resilience during lockdown, with drug offence detections increasing significantly in city- or state-wide aggregate analysis (see Langfield et al., 2021).

Instead, we hypothesised that the usual sites of drug exchange (the main markets) should have been significantly interrupted by the restrictions on pedestrian movement and social mobility and that these changes were likely masked by the displacement of drug users and drug sellers to other areas of the city. We found strong evidence to support our hypothesis with four main locales recording large declines in drug offence detections. These were the Bowen Hills rail and showground precinct, the Fortitude Valley red-light district, the Roma Street train station precinct and the Brisbane Casino precinct - all recorded considerably fewer drug offence detections during the lockdown. 
Although a notable decline was recorded in four locations, the magnitude of decline was different and we believe that this can be explained, in part, by the differential nature of each market. Bowen Hills is a mostly non-residential area which acts as the transit point for those travelling to the non-commercial and non-industrial area of the Brisbane Showgrounds. This is an area likely to be relatively free of business and pedestrian activity when there are no events being hosted. The Bowen Hills train station is also the first junction that connects all six north and western train lines heading south to the city. We don't imagine that Bowen Hills is a market of just local buyers and sellers, rather we expect Bowen Hills more closely resembles the kind of 'Public Market' that Reuter and McCoun (1992) cited as a place to which both buyers and sellers travel, taking advantage of the unique characteristics of the location which promote drug market activity. Since both parties are likely to need to travel to Bowen Hills, it is unsurprising that this market suffered the most when mobility and social distancing restrictions were put in place.

Not unlike Bowen Hills, we believe the Roma Street train station precinct is also a 'Public Market', though it likely also serves some local residents of the nearby areas of Spring Hill, Paddington and Milton. Key to understanding the Roma Street drug market is that the train station and bus interchange serve as the main arrival point for regional (and interstate) travellers who are not transiting through the Brisbane airport. It is, perhaps, not as congested as the Brisbane Central Station (central of the metropolitan train lines), but it houses most of the organisational and business offices of the Queensland Rail corporation. We think that drug offence detections at Roma Street are typically of rail and bus passengers who are transiting through the precinct, or other public transport users who are being processed at Roma Street after being apprehended on the rail network (we also note that the Roma Street terminal is directly adjacent to the Brisbane City Police Watchhouse). With interstate borders closed (Queensland Department of the Premier and Cabinet, 2020), regional travel significantly restricted (Queensland Government, 2020a, 2020c) and metropolitan public transport use at unprecedentedly low levels (Google, 2021), it is not surprising that drug offence detections at Roma Street were well below pre-lockdown trends.

The third decline was recorded in one of Brisbane's most notorious open-air/street level drug markets - Fortitude Valley - servicing the nearby red-light district and night-time economy district of Brunswick Street and surrounds (Darchen and Ladouceur, 2013; Davies, 2011; Manning et al., 2016). This area is probably most closely likened to Reuter and McCoun's (1992) description of the 'Local Market' where local drug buyers and local drug sellers meet to transact. That said, we also expect the Fortitude Valley Market serves as an export market for drug buyers who travel to purchase from local drug sellers, especially in the context of the night-time economy. Local Markets, according to Reuter and McCoun (1992), are the hardest to infiltrate and eradicate because of the dexterity of local buyers and sellers who can arrange and rearrange their location of transaction depending on immediate environment cues and local circumstances. With fewer business commuters transiting through Fortitude Valley train station during the lockdown, we expect drug buyers and sellers will have avoided the main streets as detection risks increased. Not surprisingly, our data show a decline in the number of drug offence detections in and around the Fortitude Valley Train station, but this appears to have been offset by an increase in detections on the streets of the surrounding areas. As a whole area, drug offence detections in the SA2 of Fortitude Valley did not increase or decrease during the lockdown, but this apparent stability masks a clear change in where drug buyers and sellers were interacting. This is not unexpected for a 'Local Market' which will have likely adapted quickly to the new lockdown conditions.

Finally, the fourth decline occurred in the areas surrounding the Brisbane Casino which we suspect was mostly a consequence of the temporary closure of the casino and its nearby bars and nightclubs. Most pre-lockdown drug offence detections in this area are likely to be of patrons of the night-time economy who are detected for the possession of illicit drugs. While some drug sellers are likely to frequent the area and take advantage of the night-time economy, most drugs are likely purchased elsewhere (or obtained through social supply) and brought into the Casino precinct by users. For this reason, it is difficult to know whether the Casino precinct represents a drug transaction market, or just a principal location of drug use for those who visit the night-time economy. In any case, the decline in drug offence detections is likely to have occurred during lockdown, simply because the night-time economy was closed.

Of equal interest in this study was whether and where drug market activity might have been displaced during the COVID-19 lockdown. We acknowledge that this is difficult to answer for certain, since drug offence detections are just as much (if not, moreso) a measure of police activity as they are an indicator of market activity. With that said, our results indicate that the unusually large declines in Bowen Hills, Fortitude Valley and Roma Street were offset by an increase in drug detections at specific sites or more generally on the streets of neighbouring areas. The very-inner streets of the Central Business District saw a large increase in drug offence detections, particularly in the CBD retail precinct of Queen Street Mall. We are unsure whether this increase is a consequence of displacement, or simply an increase in the visibility and vulnerability of drug user communities who traversed the city streets despite the lockdown. We expect that many more people will have been stopped and questioned by the police simply for being in the city and not abiding by government lockdown rules. This is likely to have resulted in an increase in drug offence detections, irrespective of whether the police were actually targeting drug users as a specific strategy.

The same factors are also likely to explain some of the apparent urban sprawl of drug offence detections, with there being a small number of detections spread more widely across a larger spatial field of the inner city urban landscape. New Farm, 
Kangaroo Point and Southbank - all to the east of the city - show a considerable increase in drug offence detections, but these were spread in small numbers across multiple different locations. To the south-west, a sizable and concentrated pocket of drug offence detections seems to have emerged in the retail precinct of Toowong, while another appears to have emerged to the west in the suburb of Ashgrove. To the north, there was a sprawl of detections in the region of Lutwyche, and two newly concentrated pockets in Doomben (nearby to the Doomben Racecourse) and in Hendra (a primarily commercial estate servicing the Brisbane Airport). We wonder whether these new urban locations have emerged as temporary 'Import Markets' (Reuter and McCoun 1992) as drug users/buyers stayed closer to home during lockdown but were being serviced by a smaller number of travelling drug sellers. Knowing that most drug offence detections are for possession, likely of drug users sometime after purchase, these pockets of new drug detections probably signal the position of drug users, not the location of drug sellers. In Hendra, we may have seen the temporary opening of a new public market, as drug buyers and sellers sought out locations that were inconspicuous and ripe for illicit or covert activity. Given that the Brisbane Airport had already closed to international and (most) domestic travel, it is not unreasonable to expect the surrounding commercial districts to have been less busy with commercial and other pedestrian business.

While we cannot be certain that drug offence detections signal a change in drug market behaviour, there are some insights to be gleaned from the pattern of detections we have seen across the city. For example, drug offence detections to the east of the Brisbane River increased considerably in Kangaroo Point and Southbank, but not to any great extent elsewhere in that region. This might be a consequence of different policing priorities, however we can't help but point out that both Kangaroo Point and Southbank are the only two locations to the east of the river that are accessible from the city by foot. To be sure, in SA2305 (the Brisbane Inner City) there are seven bridges which span the river from west to east. All of these connect to the eastern side of the river in either Kangaroo Point or Southbank. None of the inner city urban areas to the north of Kangaroo Point can be accessed by foot, except by the use of a public ferry. The same is true to the south of Southbank. We also note that drug offence detections seem to have increased (although in small numbers) along two of the main arterial roads leading out from the city centre. The first is heading south along the river towards Toowong and the second runs north from Bowen Hills to Lutwyche. This is not definitive evidence in favour of displacement (versus policing practice), although it does suggest that the mobility of drug users is an important factor in the spatial spread of drug offence detections away from the city.

Of course, there are several limitations which should be considered in light of our results. In particular, we model police drug offence detection data which combines drug possession, drug trafficking and other drug offences, including the possession of drug utensils and paraphernalia. For privacy reasons, spatial data for drug offences across Queensland are not disaggregated and so a more precise measure of different drug offence types is not possible. Further, as we have noted earlier, police detection data are likely to be a relatively poor proxy for drug market activity as they speak only to a very small fraction of the drug user population and for a very small fraction of actual drug market activity. To what extent the lockdown data reflects the change in police practice, we can't be certain, but it is most certainly a factor which has implications for our conclusions. Finally, we started our analysis with a summary of predictions made from a spatiotemporal GAM model. These analyses provided a critical foreground for our central argument that location specific effects were masked at higher geospatial resolutions, especially where there was displacement to nearby areas (much like we showed for Bowen Hills and Fortitude Valley). Our GAM model performed surprisingly well (accounting for $85 \%$ of the variance), but like all models the GAM is a mathematical representation of a complex process where statistical relationships (both between locations and within locations over time) are averaged. Models are imperfect and their imprecisions can have implications for the results we have summarised in this study.

To conclude, what is clear from these data is that drug markets were significantly impacted by the COVID-19 lockdown. This contradicts the extant international and Australian city- or state-wide aggregate analyses (see, for instance, Langfield et al., 2021; Langton et al., 2021) which has so far implied a significant stability and resilience of drug markets in the face of government mandated stay-at-home restrictions. We have witnessed in these data considerable local-level declines, specifically in the four main locations of Bowen Hills, Fortitude Valley, Roma Street and the Brisbane Casino, which were offset by an increase in detections elsewhere in the city. Some of this increase, we think, is a result of a change in police activity as well as the increased vulnerability of drug-using communities during a time when most other city-goers stayed home. That said, we identified several new outer-urban locations where drug offence detections increased. This suggests the emergence of new markets which we hypothesize are either import or public markets where drug sellers traveled to supply local drug buyers who could no longer easily access the main markets in large numbers. We anticipate these new urban markets will be temporary, but only further research beyond the lockdown period will be able to confirm this hypothesis. Similarly, we expect a relatively quick return to normal for the main inner city markets, especially since in Brisbane the lockdown ended after almost two months of zero community transmission. This means that, unlike in other countries, there was little to no post-lockdown risk of infection in Brisbane. For this reason alone, Australia is unique and makes for an essential site for international comparative analysis of COVID-19-related changes in drug use and crime. 
A PREPRINT - JUNE 2021

\section{References}

Adler, P. (1993). Wheeling \& dealing: An ethnography of an upper-level drug dealing \& smuggling community. Columbia University Press.

Agar, M. (1973). Ripping and running. a formal ethnography of urban heroin addicts. Seminar Press.

Andresen, M. A., \& Hodgkinson, T. (2020). Somehow I always end up alone: COVID-19, social isolation and crime in Queensland, Australia. Crime Science, 9(1), 25. https://doi.org/10.1186/s40163-020-00135-4

Ashby, M. P. J. (2020a). Changes in Police Calls for Service During the Early Months of the 2020 Coronavirus Pandemic. Policing: A Journal of Policy and Practice, 14(4), 1054-1072. https://doi.org/10.1093/police/paaa037

Ashby, M. P. J. (2020b). Initial evidence on the relationship between the coronavirus pandemic and crime in the United States. Crime Science, 9(1), 6. https://doi.org/10.1186/s40163-020-00117-6

Australian Bureau of Statistics. (2011). Australian statistical geography standard (asgs).

Australian Bureau of Statistics. (2016). Census.

Australian Bureau of Statistics. (2021). Household impacts of covid-19 survey.

Barendregt, C., van der Poel, A., \& van de Mheen, D. (2006). The rise of the mobile phone in the hard drug scene of rotterdam. Journal of Psychoactive Drugs, 38(1), 77-87. https://doi.org/10.1080/02791072.2006.10399830

Buerger, M. (1991). Cops and dealers: Enforcement strategies against the street-level drug trade.

Campedelli, G. M., Aziani, A., \& Favarin, S. (2020). Exploring the Immediate Effects of COVID-19 Containment Policies on Crime: an Empirical Analysis of the Short-Term Aftermath in Los Angeles. American Journal of Criminal Justice. https://doi.org/10.1007/s12103-020-09578-6

Campedelli, G. M., Favarin, S., Aziani, A., \& Piquero, A. R. (2020). Disentangling community-level changes in crime trends during the COVID-19 pandemic in Chicago. Crime Science, 9(1), 21. https://doi.org/10.1186/s40163-020-00131-8

Currie, G., Jain, T., \& Aston, L. (2020). Long term travel impacts of covid-19 in melbourne: Phase 1 and 2 results - overview of key findings (Report). Monash University.

Curtis, R., \& Wendel, T. (2000). Toward the development of a typology of illegal drug markets.

Curtis, R., Wendel, T., Spunt, B., \& Jay, J. (2002). We deliver: The gentrification of drug markets on manhattan's lower east side, final report. Rockville, MD: US Department of Justice.

Darchen, S., \& Ladouceur, E. (2013). Social sustainability in urban regeneration practice: A case study of the fortitude valley renewal plan in brisbane. Australian Planner, 50(4), 340-350. https://doi.org/10.1080/07293682.2013.764909

Davies, A. (2011). A case of community safety: Displacing complex 'social' problems in fortitude valley (Thesis).

Dorn, N., Murji, K., \& South, N. (1992). Traffickers: Drug markets and law enforcement. Routledge.

Eck, J. E. (1995). A general model of the geography of illicit retail marketplaces. Crime and place, 4, 67-93.

Google. (2021). Queensland covid-19 community mobility report.

Johnson, B., Hamid, A., \& Sanabria, H. (1992). Emerging models of crack distribution. In T. Mieczkowski (Ed.), Drugs, crime, and social policy: Research, issues, and concerns. Allyn; Bacon.

Johnson, L. T. (2009). Classifying drug markets by travel patterns: Testing reuter and maccoun's typology of market violence (Thesis).

Johnson, L. T. (2016). Drug markets, travel distance, and violence: Testing a typology. Crime \& Delinquency, 62(11), 14651487. https://doi.org/10.1177/0011128714568302

Langfield, C. T., Payne, J. L., \& Makkai, T. (2021). Drug offence detection during the pandemic: An ARIMA analysis of rates and regional differences in Queensland, Australia. Journal of Criminology, O(0), 00048658211007532. https: //doi.org/10.1177/00048658211007532

Langton, S., Dixon, A., \& Farrell, G. (2021). Six months in: pandemic crime trends in England and Wales. Crime Science, 10(1), 6. https://doi.org/10.1186/s40163-021-00142-z

Manning, M., Mazerolle, L., Mazerolle, P., \& Collingwood, P. (2016). Place managers in entertainment districts: The role of third party policing in shaping place manager actions. Policing and Society, 26(8), 889-906. https://doi.org/10.1080/ 10439463.2014.989848

May, T., \& Hough, M. (2004). Drug markets and distribution systems. Addiction Research \& Theory, 12(6), 549-563. https: //doi.org/10.1080/16066350412331323119

Nivette, A. E., Zahnow, R., Aguilar, R., Ahven, A., Amram, S., Ariel, B., Burbano, M. J. A., Astolfi, R., Baier, D., Bark, H.-M., Beijers, J. E. H., Bergman, M., Breetzke, G., Concha-Eastman, I. A., Curtis-Ham, S., Davenport, R., Díaz, C., Fleitas, D., Gerell, M., ... Eisner, M. P. (2021). A global analysis of the impact of covid-19 stay-at-home restrictions on crime. Nature Human Behaviour. https://doi.org/10.1038/s41562-021-01139-z

O’Sullivan, D., Rahamathulla, M., \& Pawar, M. (2020). The Impact and Implications of COVID-19: An Australian Perspective. The International Journal of Community and Social Development, 2(2), 134-151. https://doi.org/10.1177/ 2516602620937922

Payne, J. L., \& Langfield, C. T. (2021). Drug markets and COVID-19: A spatiotemporal study of drug offence detection rates in Brisbane, Australia. [pre-print]. https://doi.org/https://doi.org/10.31235/osf.io/2bxyw 
Payne, J. L., Morgan, A., \& Piquero, A. R. (2020). COVID-19 and social distancing measures in Queensland, Australia, are associated with short-term decreases in recorded violent crime. Journal of Experimental Criminology. https://doi.org/ 10.1007/s11292-020-09441-y

Payne, J. L., Morgan, A., \& Piquero, A. R. (2021). Exploring regional variability in the short-term impact of COVID-19 on property crime in Queensland, Australia. Crime Science, 10(1), 7. https://doi.org/10.1186/s40163-020-00136-3

Peristeraki, P., Bitetto, I., Carbonara, P., Carlucci, R., Certain, G., De Carlo, F., Gristina, M., Kamidis, N., Pesci, P., \& Stagioni, M. (2019). Investigation of spatiotemporal patterns in mean temperature and mean trophic level of MEDITS survey catches in the Mediterranean Sea. Scientia Marina, 83(S1), 165-174.

Piquero, A. R., Jennings, W. G., Jemison, E., Kaukinen, C., \& Knaul, F. M. (2021). Domestic violence during the covid-19 pandemic - evidence from a systematic review and meta-analysis. Journal of Criminal Justice, 74, 101806. https: //doi.org/https://doi.org/10.1016/j.jcrimjus.2021.101806

Queensland Department of the Premier and Cabinet. (2020). Queensland first to make emergency declarations in January [media release].

Queensland Government. (2020a). Queensland border restrictions.

Queensland Government. (2020b, April 30). Queensland offence rates - Open Data Portal [SBS]. Retrieved April 30, 2020, from https://www.data.qld.gov.au/dataset/offence-rates-monthly-from-july-1997

Queensland Government. (2020c). Roadmap to easing restrictions.

Reuter, P. H., \& MacCoun, R. J. (1992). Street drug markets in inner-city neighbourhoods. Urban America, Rand, Santa Monica, California, 227-251.

Reynald, D. M. (2010). Guardians on guardianship: Factors affecting the willingness to supervise, the ability to detect potential offenders, and the willingness to intervene. Journal of Research in Crime and Delinquency, 47(3), 358-390. https: //doi.org/10.1177/0022427810365904

St. Jean, P. (2007). Pockets of crime: Broken windows, collective efficacy, and the criminal point of view. University of Chicago Press. https://doi.org/https://chicago.universitypressscholarship.com/view/10.7208/chicago/9780226775005.001. 0001/upso-9780226774985.

Stickle, B., \& Felson, M. (2020). Crime Rates in a Pandemic: the Largest Criminological Experiment in History. American Journal of Criminal Justice, 45(4), 525-536. https://doi.org/10.1007/s12103-020-09546-0

Wood, S. N. (2017). Generalized additive models: an introduction with $R$ (2nd). CRC press.

Wood, S. N. (2021). Inferring UK COVID-19 fatal infection trajectories from daily mortality data: Were infections already in decline before the UK lockdowns? Biometrics, $n / a(\mathrm{n} / \mathrm{a})$. https://doi.org/https://doi.org/10.1111/biom.13462 
Figure 1: Brisbane Local Government Area with Inner City Brisbane SA2 (shaded)

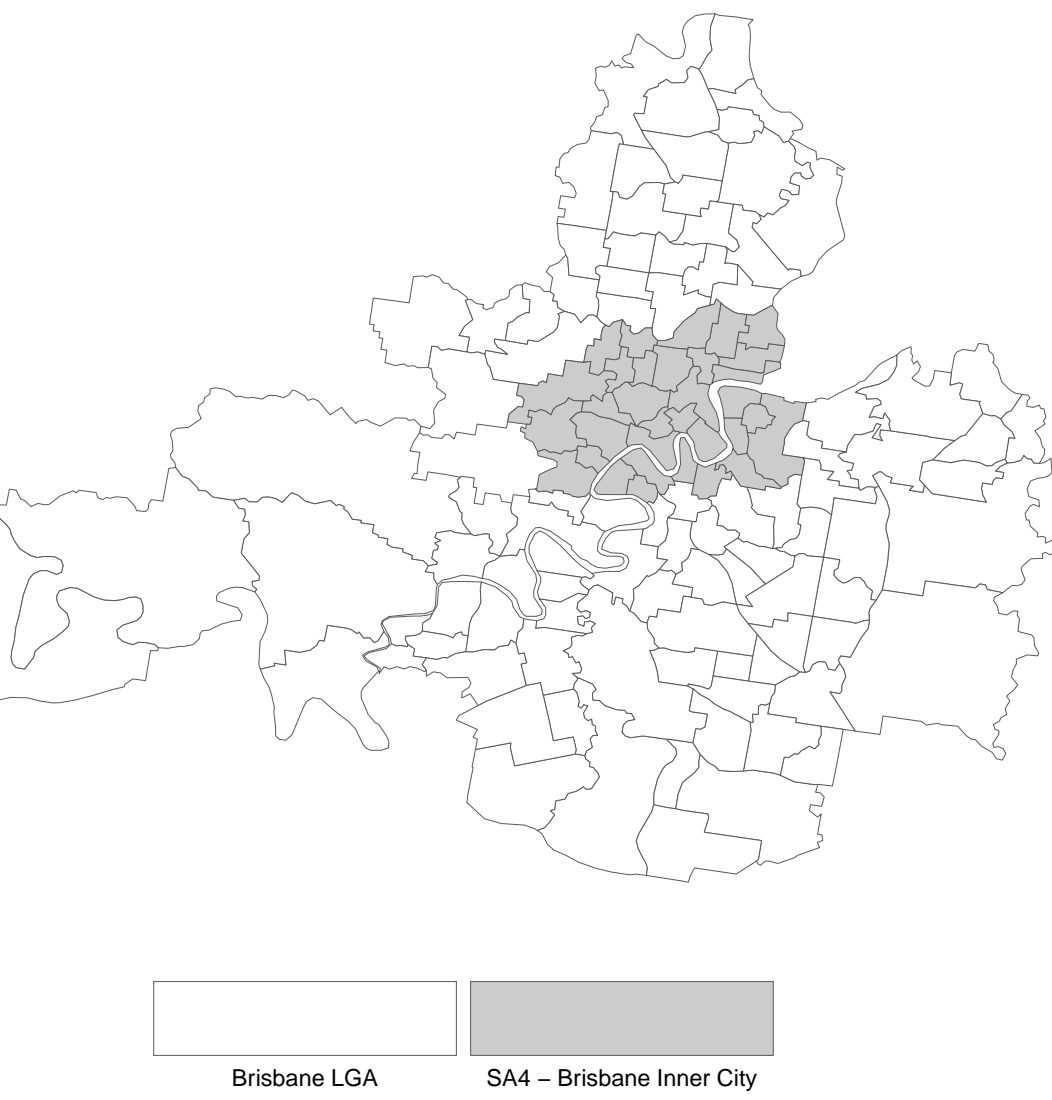

Source: Queensland Government Open Data Portal - Computer file 
Figure 2: Brisbane Inner City SA2s and Meshblocks

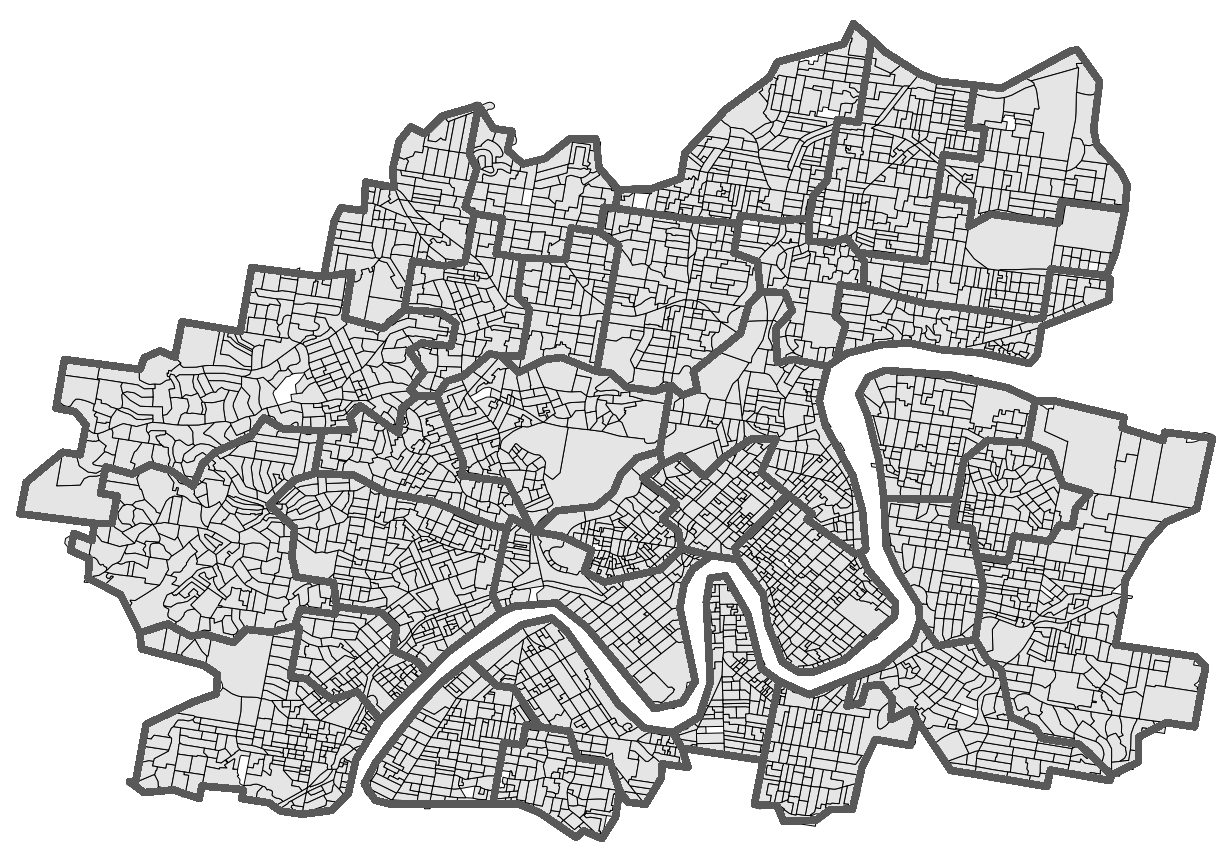

Source: Queensland Government Open Data Portal [computer file] 
Figure 3: Visual representation of a GAM estimated geospatial thin-plate spline / tensor product (Drug Detections, Brisbane LGA)

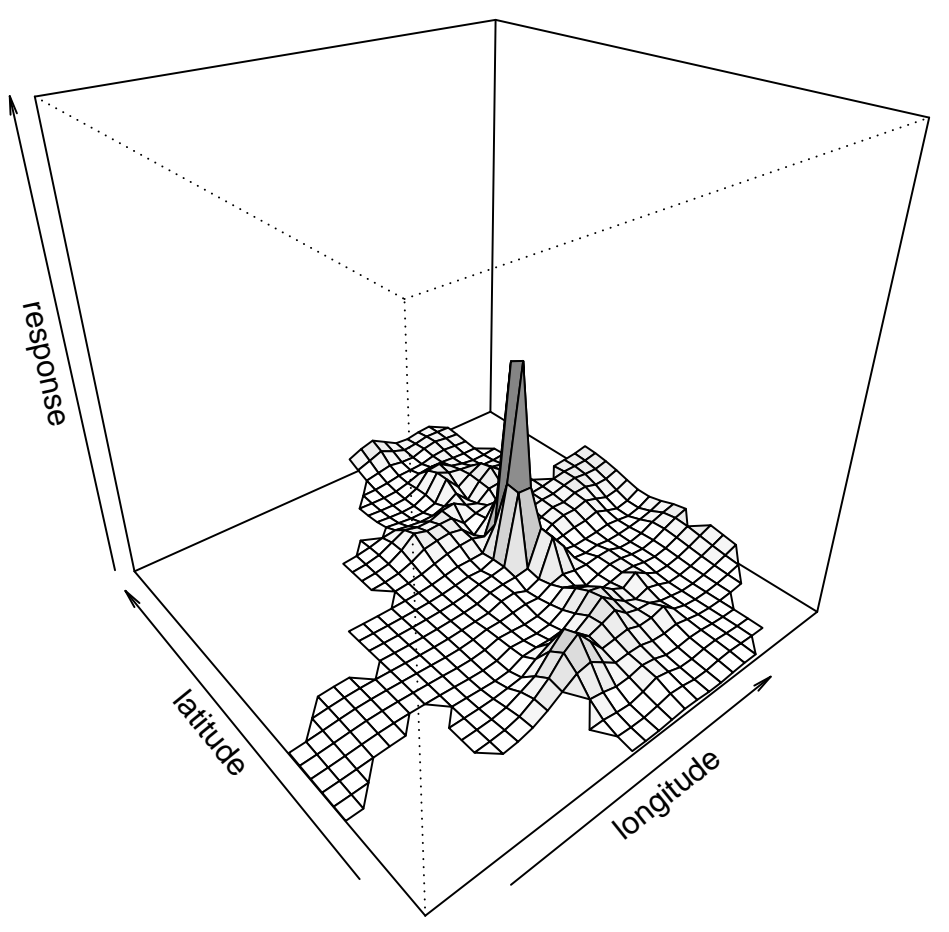

Source: Queensland Government Open Data Portal [computer file] 
A PREPRINT - JUNE 2021

Figure 4: Spatiotemporal GAM model of pre-COVID drug offence detection rates (April 2016-March 2020)

Table 1: Spatiotemporal GAM model of pre-COVID drug offence detection rates (April 2016-March 2020)

\begin{tabular}{|c|c|c|c|c|c|}
\hline Main effects & Specification & Mean (sd) & b & s.e & $\mathbf{p}$ \\
\hline Inner-city region & (Dichotomous) & $0.25(0.44)$ & -2.00 & 0.50 & 0.00 \\
\hline City centre & (Dichotomous) & $0.02(0.12)$ & 2.26 & 0.63 & 0.00 \\
\hline Fortitude Valley & (Dichotomous) & $0.01(0.09)$ & -1.85 & 0.53 & 0.00 \\
\hline Accommodation and Entertainment Density & (Scaled - Number of outlets) & $0(1)$ & 0.16 & 0.11 & 0.13 \\
\hline Retail & (Scaled - Number of outlets) & $0(1)$ & 0.16 & 0.07 & 0.02 \\
\hline Relative Economic Disadvantage & (Scaled - IER Index) & $0(1)$ & -0.69 & 0.11 & 0.00 \\
\hline Relative Education/Occupation Disadvantage & (Scaled - IEO Index) & $0(1)$ & 0.03 & 0.13 & 0.83 \\
\hline Young adults & (\% of residents aged $15-24)$ & $14.7(4.6)$ & -0.05 & 0.02 & 0.00 \\
\hline Overseas born residents & (\% of residents born overseas) & $29.4(10.8)$ & -0.02 & 0.01 & 0.03 \\
\hline Inner-city*IER & interaction & -- & 0.27 & 0.18 & 0.14 \\
\hline Inner-city*IEO & interaction & -- & -0.07 & 0.23 & 0.75 \\
\hline Inner-city*young adults & interaction & -- & 0.04 & 0.27 & 0.11 \\
\hline Inner-city*overseas born & interaction & -- & 0.05 & 0.02 & 0.00 \\
\hline Constant/intercept & -- & -- & 3.04 & 0.31 & 0.00 \\
\hline \multicolumn{3}{|l|}{ GAM estimated smoothed effects } & \multicolumn{2}{|c|}{ EDF } & $\mathbf{p}$ \\
\hline \multicolumn{3}{|l|}{ Spatiotemporal Trend (longitude, latitude, year) } & \multicolumn{2}{|c|}{220} & 0.00 \\
\hline \multicolumn{3}{|c|}{ Spatiotemporal Seasonality (longitude, latitude, year) } & \multicolumn{2}{|c|}{25} & 0.00 \\
\hline \multicolumn{6}{|l|}{ Model fit diagnostics } \\
\hline \multicolumn{2}{|l|}{$\mathrm{N}$} & & \multicolumn{3}{|c|}{6096} \\
\hline \multicolumn{2}{|l|}{ Negative Binomial Scale } & & \multicolumn{3}{|c|}{3.46} \\
\hline \multicolumn{2}{|l|}{ REML } & & \multicolumn{3}{|c|}{17188} \\
\hline \multicolumn{2}{|l|}{ Adjusted $\mathrm{R}^{2}$} & & \multicolumn{3}{|c|}{0.85} \\
\hline \multicolumn{2}{|l|}{ AIC } & & \multicolumn{3}{|c|}{20456.77} \\
\hline
\end{tabular}

Notes: EDF = estimated degrees of freedom, REML = Restricted Maximum Likelihood, AIC = Aikaike Informaiton Criteria

Source: Queensland Government Open Data Portal

Source: Queensland Government Open Data Portal [computer file] 
Figure 5: GAM generated prediction and Bayesian intervals for selected Meshblocks, Brisbane Inner City
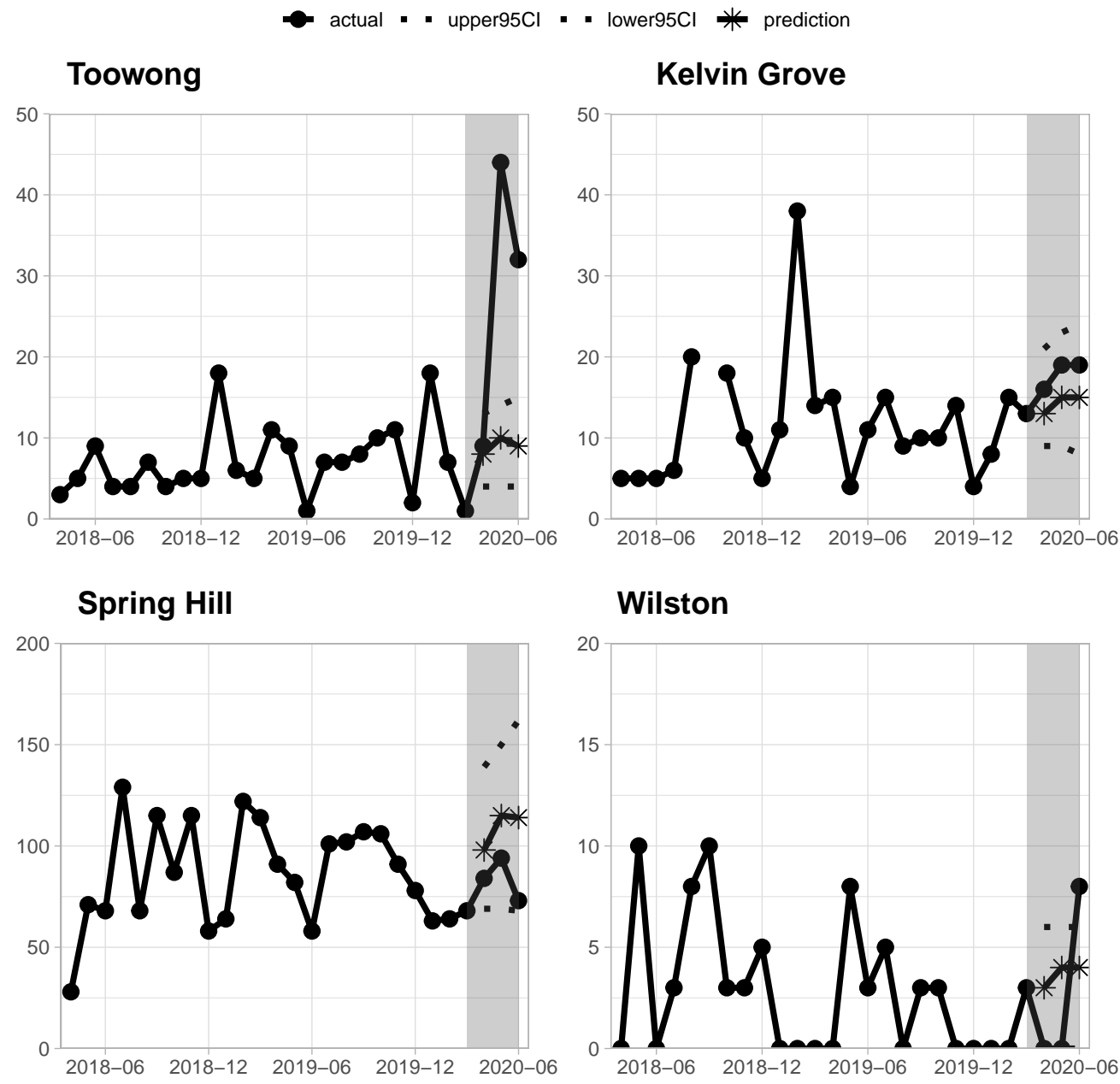

Source: Queensland Government Open Data Portal [computer file] 
Figure 6: Summary of GAM prediction outcomes, Brisbane Inner City

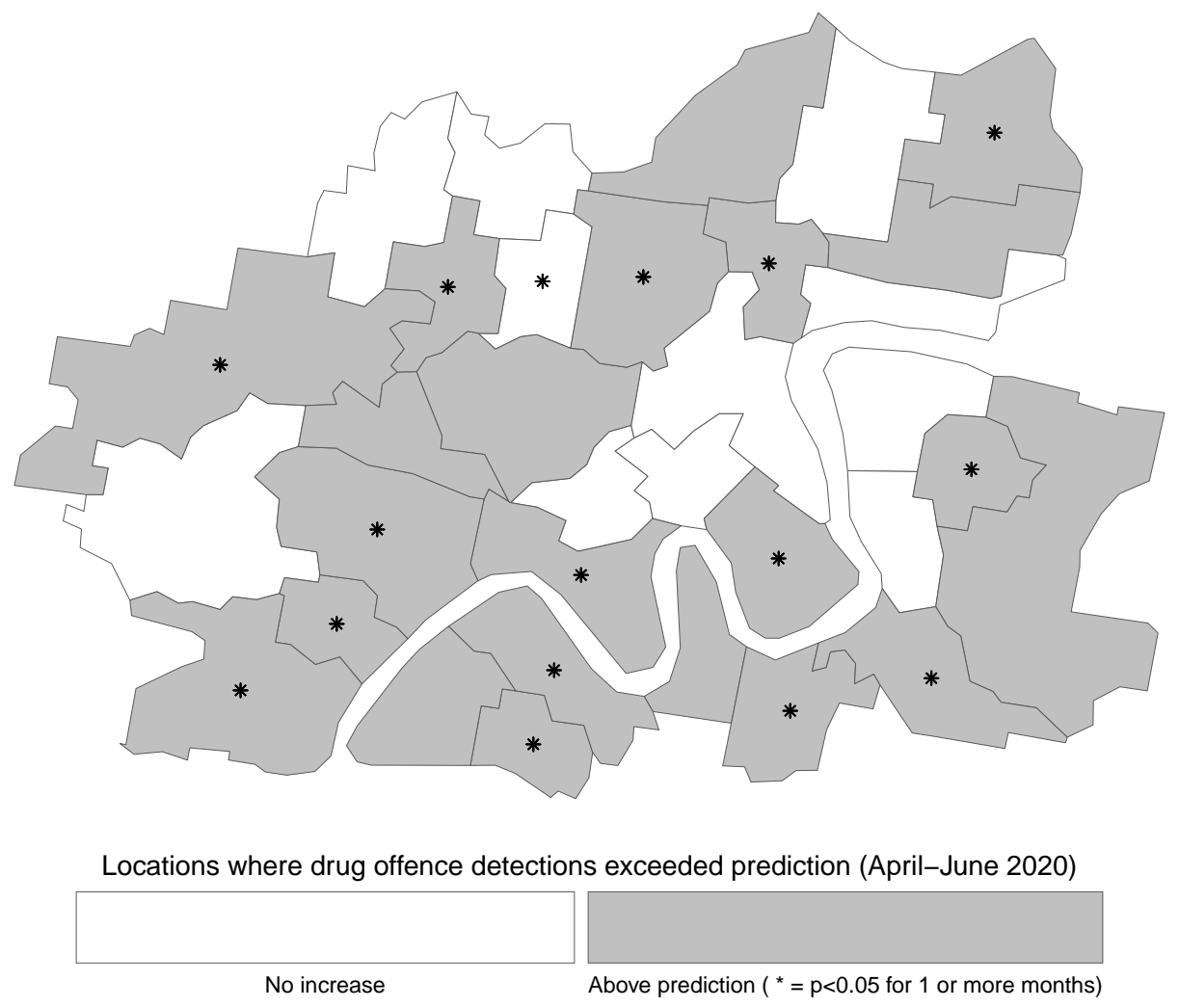

Source: Queensland Government Open Data Portal [computer file] 
Figure 7: Relative increase in drug offence detections (excess offences as a percentage of the upper 95\% prediction interval, April-June 2020), Brisbane Inner City

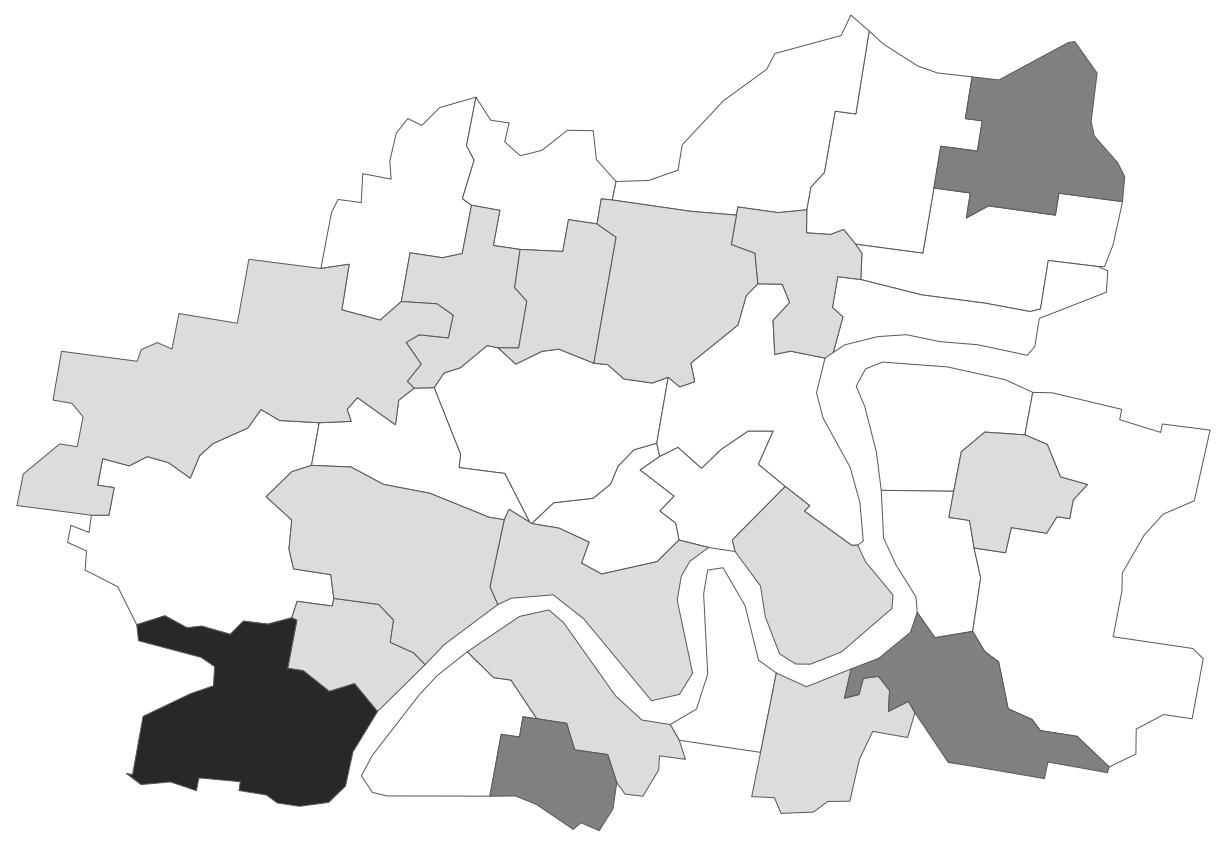

Overall excess detections (percent of the upper 95\% prediction, April-June 2020)

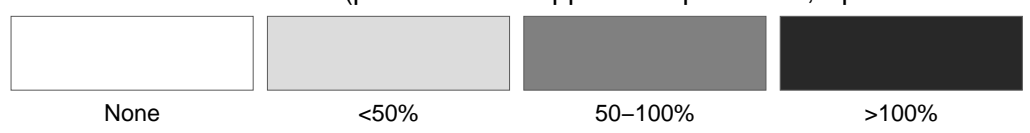

Source: Queensland Government Open Data Portal [computer file] 
Figure 8: Drug offence detections pre-lockdown (Jan-Mar 2020), Brisbane Inner City

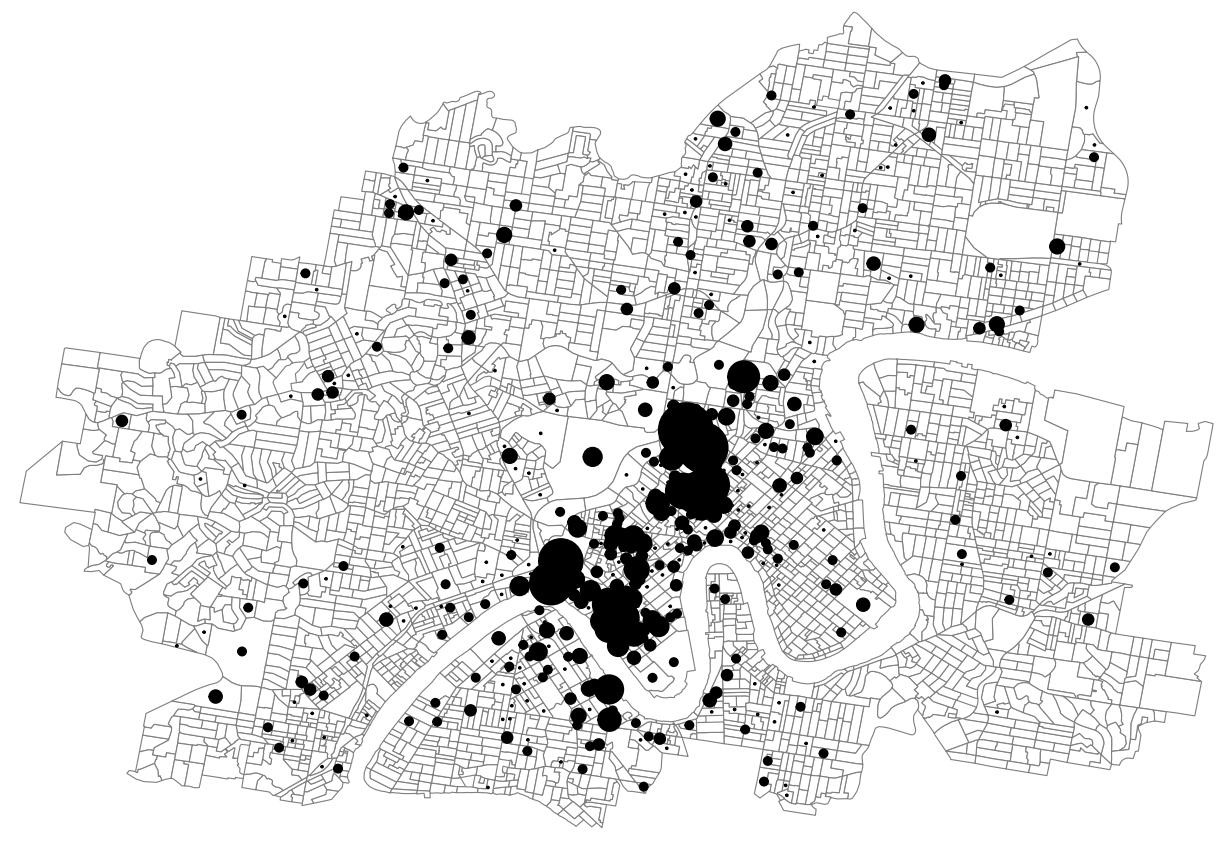

Drug Offence Detection Count (Jan-Mar 2020)

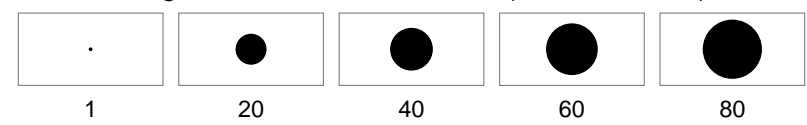

Source: Queensland Government Open Data Portal [computer file] 
Figure 9: Numerical change in drug offence detections during lockdown (Apr-Jun 2020), Brisbane Inner City

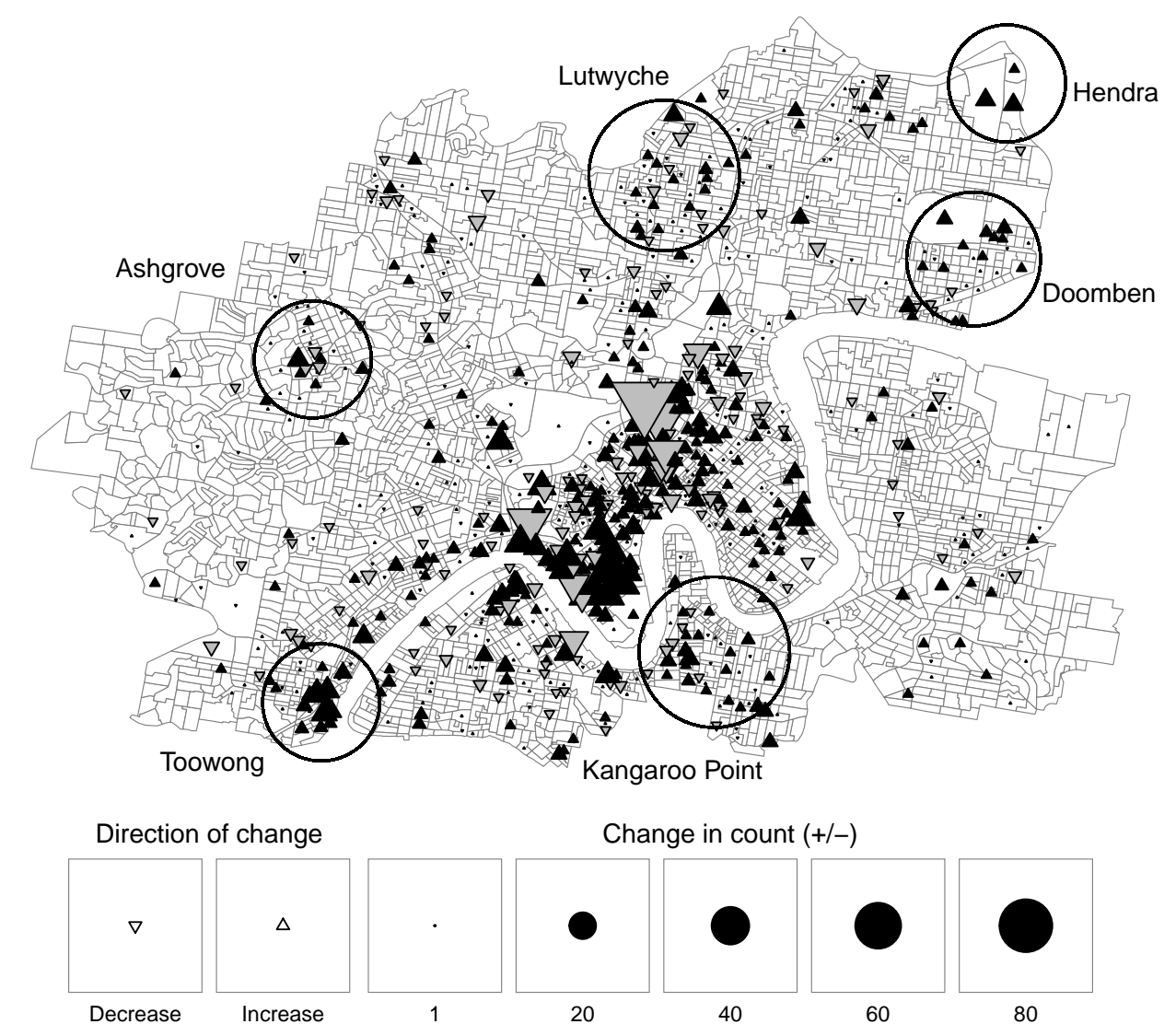

Note: Circles indicate pockets of notable increase in outer urban locations Source: Queensland Government Open Data Portal [computer file] 
Figure 10: Numerical change in drug offence detections during lockdown (Apr-Jun 2020), Brisbane CBD
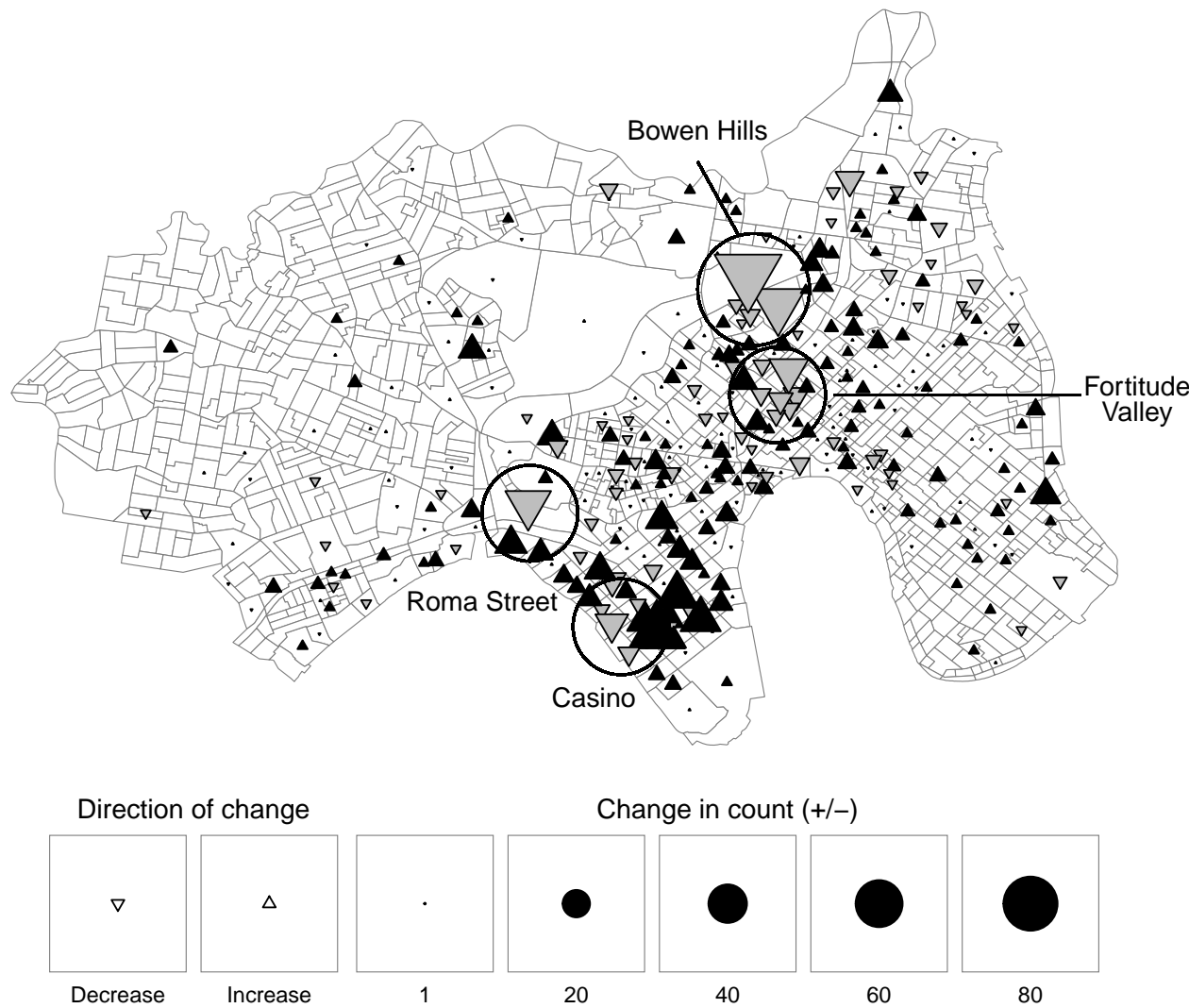

20

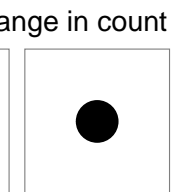

40

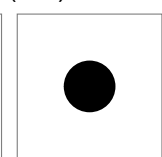

60

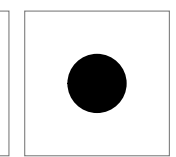

80

Note: Circles indicate pockets of notable decrease in the inner CBD

Source: Queensland Government Open Data Portal [computer file] 